\title{
CD4/CD8 double negative mycosis fungoides with PD-1 (CD279) expression-a disease of follicular helper T-cells?
}

\author{
Kempf, Werner ; Kazakov, Dmitry V ; Cipolat, Claudio ; Kutzner, Heinz ; Roncador, Giovanna ;
} Tomasini, Dario

\begin{abstract}
CD4/CD8 double negative mycosis fungoides (MF) is a rare phenotypic variant of this epidermotropic cutaneous T-cell lymphoma. Clinically, this MF form manifests with unusual appearances such as annular lesions confined to one body region as in our patient in whom the lesions were found on the left lower leg. The cellular origin of CD4/CD8 double negative MF is unknown. In our case, the intraepidermal CD4/CD8 double negative clonal T-lymphocytes (CD2+, CD4-, CD8-, CD30-, betaF1+) expressed programmed death-1 but were negative for CXCL-13 and cytotoxic molecules (TIA-1, granzyme B, perforin). Our observation may give an insight into the histogenesis of this unique MF variant and may also be of therapeutic significance because programmed death-1 may serve as a target for therapeutic intervention.
\end{abstract}

DOI: https://doi.org/10.1097/DAD.0b013e31825b26d1

Posted at the Zurich Open Repository and Archive, University of Zurich

ZORA URL: https://doi.org/10.5167/uzh-67832

Journal Article

Accepted Version

Originally published at:

Kempf, Werner; Kazakov, Dmitry V; Cipolat, Claudio; Kutzner, Heinz; Roncador, Giovanna; Tomasini, Dario (2012). CD4/CD8 double negative mycosis fungoides with PD-1 (CD279) expression-a disease of follicular helper T-cells? American Journal of Dermatopathology, 34(7):757-761.

DOI: https://doi.org/10.1097/DAD.0b013e31825b26d1 


\section{The American Journal of Dermatopathology CD4/CD8 double negative mycosis fungoides with PD-1 (CD279) expression - a disease of follicular helper T cells? \\ --Manuscript Draft--}

\begin{tabular}{|c|c|}
\hline Manuscript Number: & AJD-D-12-00002R2 \\
\hline Full Title: & $\begin{array}{l}\text { CD4/CD8 double negative mycosis fungoides with PD-1 (CD279) expression - a } \\
\text { disease of follicular helper T cells? }\end{array}$ \\
\hline Article Type: & Extraordinary Case Report \\
\hline Keywords: & mycosis fungoides, cutaneous T-cell lymphoma, CD8, PD-1 \\
\hline Corresponding Author: & $\begin{array}{l}\text { Werner Kempf, MD } \\
\text { University Hospital Zürich } \\
\text { Zürich, Zürich SWITZERLAND }\end{array}$ \\
\hline \multicolumn{2}{|l|}{$\begin{array}{l}\text { Corresponding Author Secondary } \\
\text { Information: }\end{array}$} \\
\hline Corresponding Author's Institution: & University Hospital Zürich \\
\hline \multicolumn{2}{|l|}{$\begin{array}{l}\text { Corresponding Author's Secondary } \\
\text { Institution: }\end{array}$} \\
\hline First Author: & Werner Kempf, MD \\
\hline \multicolumn{2}{|l|}{ First Author Secondary Information: } \\
\hline \multirow[t]{6}{*}{ Order of Authors: } & Werner Kempf, MD \\
\hline & Dmitry V Kazakov \\
\hline & Claudio Cipolat \\
\hline & Heinz Kutzner \\
\hline & Giovanna Roncador \\
\hline & Dario Tomasini \\
\hline \multicolumn{2}{|c|}{ Order of Authors Secondary Information: } \\
\hline Abstract: & $\begin{array}{l}\text { CD4/CD8 double negative mycosis fungoides (MF) is a rare phenotypic variant of this } \\
\text { epidermotropic cutaneous T-cell lymphoma. Clinically, this MF form manifests with } \\
\text { unusual appearances such as annular lesions confined to one body region like in our } \\
\text { patient in whom the lesions were found on the left lower leg. The cellular origin of } \\
\text { CD4/CD8 double negative MF is unknown. In our case, the intraepidermal CD4/CD8 } \\
\text { double negative clonal T-lymphocytes (CD2+, CD4-, CD8-, CD30-, betaF1+) } \\
\text { expressed PD-1, but were negative for CXCL-13 and cytotoxic molecules (TIA-1, } \\
\text { granzyme B, perforin). Our observation may give insight into the histogenesis of this } \\
\text { unique MF variant and may also be of therapeutic significance since PD-1 may serve a } \\
\text { target for therapeutic intervention. }\end{array}$ \\
\hline
\end{tabular}


LWW Copyright Transfer and Disclosure Form
Click here to download LWW Copyright Transfe

Click here to download LWW Copyright Transfer and Disclosure Form: Copyright WK AJD-D12-00002R2.pdf 


\section{Cover letter R2 AJD-D-12-00002}

Dear Dr. Sangüeza, dear Omar

Enclosed please find the revised manuscript " CD4/CD8 double negative mycosis fungoides with PD-1 (CD279) expression - a disease of follicular helper T cells?" (AJD-D-12-00002). We are very grateful for your comments and the comments of the reviewers. Enclosed please find the point-by-point answers to their comments. The corresponding changes in the manuscript has been highlighted by red.

We hope that the revised manuscripts fulfills the requirements and very high standard for publication in the Journal. We very much appreciate your evaluation of our manuscript.

Kind regards,

Werner

Point-by-point answers to the reviewer's comments

Reviewer \#1:

(1) I am curious about the expression of PD-1 on various cells, and did not see this addressed in the report. It may be beyond the scope of a case report, but is PD-1 expression restricted to CD4 positive T cells and CD4-CD8 negative cells? Is it ever seen on CD8 positive cells? When? Is it reported in other instances of CD4/CD8 negative T cells? What $\mathrm{B}$ cells express this?

Reply: PD-1 expression can be induced in T-cells, B cells, and dendritic cells upon activation. In contrast, follicular T helper cells constitutiveky express PD-1 at high levels (Francisco et al. Immunol Rev 2010;236:219-242). To the best of our knowledge, PD-1 expression previously not been reported in CD4 CD8 double negative T-cells. A very recent publication (Baitsch et al. PLoS One. 2012;7(2):e30852. Epub 2012 Feb 8) reported expression of PD-1 in CD8-positive T-cells. Expression of PD-1 by B-cells has been observed in the study by Xerri $L$ et al. Programmed death 1 is a marker of angioimmunoblastic T-cell lymphoma and B-cell small lymphocytic lymphoma/chronic lymphocytic leukemia. Hum Pathol 2008; 39:1050-8. This issue has been addressed in the revised rmanuscript on page 6 , second paragraph.

(2) I think the authors meant to say UVB "narrow band" rather than "barrow band." Reply: We apologize for this typographical error which was corrected in the revised manuscript.

Reviewer \#2:

(1) This is a very interesting case that deserves publication. However, I believe this is a case of pagetoid reticulosis with a null-phenotype rather than conventional MF. The lesions are confined to the left leg and the histological pattern and immunophenotype are more consistent with PR than MF.

Reply: The term pagetoid reticulosis according to current lymphoma classification is restricted to a unilesional form of MF. Thus we did not employ this term in our patient who had two separate lesions on the left lower leg.

(2) PD-1 expression is not specific for FTH cells. High percentage of Sezary cells (about 2/3 of cases) are PD-1 positive and PD-1 expression is also seen in other inflammatory conditions, especially viral infections. I believe bcl6/CD3 coexpression would be strong supporting data for the proposed origin of these cells.

Reply: We fully agree that expression of PD-1 is not restricted or specific for CD4/CD8 
double negative MF, since it is quite often seen in Sézary syndrome. Nevertheless, the expression of PD-1 in this unusual form of MF has not been described before and may shed light on the histogenesis of this variant. In our case, the PD-1 positive cells also express CD3 and partially bcl-6. These findings demonstrate that they belong to follicular helper T cells. This information is provided on page 5, first paragraph of the revised manuscript.

(3) "The lack of expression of CXCL-13 and CD10 as markers expressed by follicular T helper cells under physiological conditions may be suggestive of a possible origin of this unusual variant of MF from neoplastic follicular T helper cells." This sentence does not make any sense to me.

Reply: The PD-1 positive cells in our case are the neoplastic cells. In neoplastic lymphocytes, a loss of markers is often found and may be a further argument for the neoplastic nature of the PD-1 cells. We changed the sentence to clarify this point on page 6 last paragraph and page 7 , first paragraph.

(4) Please correct lymphoma not otherwise unspecified (NOS) on page 7, it should specified instead.

Reply: This mistake has been corrected in the revised manuscript $\mathrm{R} 2$.

(5) Page 4 should be "narrow band" rather than "barrow band"

Reply: This typographical error was corrected in the revised manuscript.

(6) We really don't need the names of topical steroid creams, but if you decide to keep them Mometasone furoate is misspelled twice.

Reply: This error was corrected in the revised manuscript. 
CD4/CD8 double negative mycosis fungoides with PD-1 (CD279) expression - a disease of follicular helper $\mathbf{T}$ cells?

\section{Authors:}

Werner Kempf, MD (1, 2), Dmitry V. Kazakov, MD, PhD (3), Claudio Cipolat (4), Heinz Kutzner, MD (5), Giovanna Roncador, MD, PhD (6), Dario Tomasini, MD (7)

\section{Institutions:}

(1) Kempf und Pfaltz, Histologische Diagnostik, Zürich, Switzerland

(2) Department of Dermatology, University Hospital, Zürich, Switzerland,

(3) Department of Pathology, Faculty of Medicine in Pilsen, Charles University in Prague, Czech Republic

(4) Dermatology Practice, Dübendorf, Switzerland

(5) Dermatopathologie Friedrichshafen Bodensee, Friedrichshafen, Germany;

(6) Centro Nacional de Investigaciones Oncologicas, Madrid, Spain

(7) Department of Dermatology, Hospital of Busto Arsizio, Busto Arsizio, Italy.

Running title: $\quad$ PD-1 positive CD4/CD8 double negative mycosis fungoides

\section{Corresponding author:}

Werner Kempf, MD

Kempf und Pfaltz

Histologische Diagnostik

Seminarstrasse 1

CH-8042, Zurich

Switzerland

Tel +41-44-2333377

Fax +41-44-2333378

e-mail kempf@kempf-pfaltz.ch 


\begin{abstract}
CD4/CD8 double negative mycosis fungoides (MF) is a rare phenotypic variant of this epidermotropic cutaneous T-cell lymphoma. Clinically, this MF form manifests with unusual appearances such as annular lesions confined to one body region like in our patient in whom the lesions were found on the left lower leg. The cellular origin of CD4/CD8 double negative $\mathrm{MF}$ is unknown. In our case, the intraepidermal CD4/CD8 double negative clonal $\mathrm{T}$ lymphocytes (CD2+, CD4-, CD8-, CD30-, betaF1+) expressed PD-1, but were negative for CXCL-13 and cytotoxic molecules (TIA-1, granzyme B, perforin). Our observation may give insight into the histogenesis of this unique MF variant and may also be of therapeutic significance since PD-1 may serve a target for therapeutic intervention.
\end{abstract}

Key words: mycosis fungoides, cutaneous T-cell lymphoma, CD8, PD-1 


\section{Introduction}

Mycosis fungoides (MF) is the most common primary cutaneous lymphoma and shows a broad clinicopathologic as well as prognostic spectrum. (1), (2). CD4/CD8 double negative MF is a rare phenotypic variant. In a recent series, this double negative phenotype has been found in 18 (12\%) of 140 patients with early stage MF. (3) Unusual clinical presentations including localized, hypopigmented and ichthyosiform have been observed to be overrepresented in that cohort. The authors of the original series discussed issues concerning the origin of CD4-CD8- neoplastic cells in MF as to whether they could represent a malignant counterpart of the normal subpopulation of lymphocytes or derive from antigen-driven $\mathrm{T}$ cells that lost expression of both markers. (3). Herewith we describe a MF patient with this peculiar immunophenotype and demonstrate that the CD4-CD8- in our case expressed the programmed death-1 (PD-1), an inhibitory member of the CD28 family located on chromosome 2q37. (4) PD-1 is expressed by a specific subset of $\mathrm{T}$ cells that are normally present in germinal centers with a helper function for follicular B cells (follicular helper $\mathrm{T}$ cells, $\mathrm{T}_{\mathrm{FH}}$ cells). These cells are characterized by a unique gene expression profile distinct from those of other naive, memory, and effector T helper subsets. (5) PD-1 expression is a characteristic feature of primary cutaneous CD4-positive small/medium-sized T-cell lymphoma (CD4+ SMPTL) (6) and in angioimmunoblastic T-cell lymphoma. (7), (8) We report for the first time the expression of PD-1 in CD4/CD8-double negative MF and discuss its significance.

\section{Material and methods}

Biopsy specimens were fixed in $10 \%$ buffered formalin and sections were routinely processed and embedded in paraffin. Serial 4 micrometer-thick sections were cut for hematoxylin and eosin stains as well as immunohistochemical stains. The antibodies used for immunohistochemistry included: CD2 (1:50, Novocastra/Leica-Microsystems, Heerbrugg, Switzerland), CD3 (1:75, Dako, Glostrup, Denmark), CD4 (1:2, Novocastra/LeicaMicrosystems, Heerbrugg, Switzerland), CD7 (1:25, Dako, Glostrup, Denmark), CD8 (1:400, Dako, Glostrup, Denmark), CD10 (1:100; Novocastra/Leica-Microsystems, Heerbrugg, Switzerland), CD20 (1:600, Dako, Glostrup, Denmark), CD30 (1:75; Novocastra/LeicaMicrosystems, Heerbrugg, Switzerland), CD45RO (RTU, Novocastra/Leica-Microsystems, Heerbrugg, Switzerland), CD45RA (1:100; Novocastra/Leica-Microsystems, Heerbrugg, Switzerland), CD56 (RTU, Novocastra/Leica-Microsystems, Heerbrugg, Switzerland), TIA-1 (1:50, Immunotech Marseille, France), beta F1 (1:50, Thermo Scientific, Germany), TCR 
gamma/delta (1:100, Thermo Scientific, Germany), PD-1 (1:10, developed by G. Roncador, MD PhD, Madrid, Spain), CXCL-13 (1:10; R\&D Systems, Abingdon, UK), EBER in situ hybridization (RTU, Novocastra/Leica-Microsystems, Heerbrugg, Switzerland). Appropriate positive controls were included.

\section{Case Report}

A 70-year old woman presented with long-standing erythematous patches on the on the left lower leg (Fig. 1). The lesions had developed 5 years ago as slightly hypopigmented macular lesions. The annular erythematous margin had appeared 6 months before consultation. Family history revealed lymphocytic leukemia in a grandchild of the patient. The patient was treated for hypothyroidism, but otherwise was healthy. Due to accentuated margins and clinical resemblance to a fungal infection, the patient had been treated with topical antimycotics, with no success. Physical examination did not show enlarged lymph nodes. Results of hematologic examination of peripheral blood, serologic findings (LDH) as well as radiologic staging including computer tomography of the chest and abdomen did not reveal abnormalities. Patch testing performed in the phase of complete remission did not show delayed type hypersensitivity to standard allergens. Following histopathological diagnosis, the patient was treated with UVB narrow band $(311 \mathrm{~nm})$ (three times per week) over a period of 10 weeks and topical steroids (mometasone furoate cream, once per day for 5 days per week) for 5 weeks. This treatment resulted in complete remission. One month after the treatment has been finished, a local relapse with a solitary slightly infiltrated annular lesion on the left lower leg was observed with partially responded to topical steroids (halometasone cream) applied over a period of three weeks with partial remission. The patient discontinued treatment since she was afraid of side effects of topical steroids and since she was not disturbed by the disease. Stable disease with a persisting solitary annular lesion was observed during follow-up of 8 months.

\section{Histopathological findings}

The epidermis was slightly acanthotic, with variable degree of spongiosis. Discrete parakeratotic cornification was present (Fig. 2). The epidermis was heavily infiltrated by small lymphocytes with chromatin dense nuclei, some of them with irregular nuclear contours (Fig 3). In the upper dermis, the lymphoid infiltrate was mainly arranged around blood vessels, but additionally a focal interstitial component was present. Eosinophilic granulocytes and plasma cells were not found.

\section{Immunohistochemical features}


Both intraepidermal and intradermal lymphocytes expressed CD2, CD3, and beta-F1, but intraepidermal lymphocytes were negative for CD4 and CD8 (Figs 4, 5). Approximately 70\% of the intraepidermal lymphocytes expressed CD7. More than $90 \%$ of the intraepidermal lymphocytes expressed PD-1 and less than 10\% showed reactivity for CXCL-13 (Fig 5). Bcl6 was expressed by $30 \%$ of the intraepidermal lymphocytes. The lymphocytes located in the epidermis were negative for CD45RO, whereas the dermal lymphocytes expressed CD45RO and CD4. CD8 and FOXP3 stained a few dermal lymphocytes, whereas no immunopositivity for the two markers was seen in the epidermal component. CD10, CD20, CD30, CD45RA, CD56 and TIA, perforin and granzyme B were not expressed. MUM1 labeled few lymphocytes both in the epidermal and dermal component. Staining for T-cell receptor (TCR) delta chain and in situ hybridization for EBV (EBER) were negative.

\section{Molecular biological assays}

T-cell receptor (TCR) rearrangement studies were performed using a multiplex polymerase chain reaction (PCR) with denaturing gradient gel electrophoresis as described elsewhere (9) and revealed a monoclonal rearrangement of TCR gamma genes.

\section{Discussion}

The spectrum of CD4/CD8 double negative cutaneous T-cell lymphomas reported in the literature encompasses MF, pagetoid reticulosis, gamma/delta-positive cutaneous T-cell lymphoma, HTLV-1 associated adult T-cell lymphoma/leukemia, and cases which can be classified as cutaneous peripheral T-cell lymphoma, unspecified according to the WHO classification (2008; 4th edition) (10), (11), (12), (13), (14), (15) . Less than 35 cases of CD4/CD8 double negative early MF have been reported since the first description in 1993 by Ralfkiaer and coworkers (16), (17), (3) , (18), (19) Our case supports the observation of Hodak et al that CD4/CD8 double negative MF is often associated with an unusual clinical presentation as in our patient in whom CD4/CD8 double negative MF clinically presented with annular and centrally hypopigmented lesions confined to the left lower leg as one body region also referred to as localized MF. Except for the expression of CD30 in early MF, none of the phenotypic MF variants appears to be of prognostic significance. (20). Due to the fact that cases of $\mathrm{CD} 4 / \mathrm{CD} 8$ double negative $\mathrm{MF}$ had not been recognized prior to their work, Hodak et al considered the possibility that this variant of MF might be unique to the Middle East. (3) Our patient is of Swiss origin. In conjunction with previous reports our observation confirms that $\mathrm{CD} 4 / \mathrm{CD}$ double negative MF occurs also in countries of central/western Europe. (16), (17), (19). 
In contrast to the majority of the previously reported cases of CD4/CD8 double negative MF cases, the intraepidermal CD4 and CD8 negative tumor cells in our patient did not express cytotoxic molecules (TIA-1, granzyme B, perforin) indicating that the tumor cells do not belong to cytotoxic T-cells. The classic $\mathrm{CD} 4+$ form of $\mathrm{MF}$ is considered to represent a neoplasm derived from memory $\mathrm{T}$ helper cells. (21) The cellular origin of CD4/CD8 double negative MF, however, is unknown. In our case, the intraepidermal CD4/CD8 double negative clonal lymphocytes expressed PD-1. PD-1 expression in CTCL including MF has little been investigated to date and the results appear controversial. Roncador et al found PD-1 positivity was found in 4 out of 5 cases $(80 \%)$. In contrast, Wada et al detected PD-1 immunoreactivity only 15 of 30 MF cases (50\%). (8), (22) In two most recent articles, Cetinözman et al. reported PD-1 in only a subset of 2 out of 21 MF cases (9\%) (23), whereas Kantekure et al detected PD-1 positive T cells in all 9 patch and plaque MF cases, with 7 of the 9 cases showing more than $25 \%$ of the atypical lymphocytes expressing PD-1. (24) These differences may be due to different antibodies and immunohistochemical protocols well as due to different cut-off levels for positivity. There was no specification as to whether these cases manifested the usual and most common CD4+CD8- phenotype.

Expression of PD-1 characterizes follicular helper $\mathrm{T}$ cells $\left(\mathrm{T}_{\mathrm{FH}}\right)$, which are normally present in germinal centers and possess helper function for B-cells. (4) PD-1 may be expressed on activated T cells and B cells (25), (26). PD-1 is a negative regulator of T cell activation and proliferation that mediates suppressive action by binding to its ligands PD-L1 and PD-L2. (27) In the context of lymphomas, PD-1 cells have been found to be expressed in nodal angioimmunoblastic T-cell lymphoma and in primary cutaneous lymphomas classified as CD4+SMPTL and identical lesions diagnosed by others as pseudolymphomatous folliculitis or nodular T-cell pseudolymphoma. (7), (28), (6) It can be speculated that CD4/CD8 double negative MF represents a neoplastic counterpart of $\mathrm{T}_{\mathrm{FH}}$ cells. Alternatively, expression of PD1 may be upregulated as the result of activation of antigen-stimulated T cells with loss of CD4 and CD8 since PD-1 can be expressed on activated T-cells. Remarkably, the PD-1 positive tumor cells in our case did not show expression of CXCL-13 and bcl-6 only in 30\%, whereas tumor cells in cutaneous CD4+ SMPTL express both markers. (6) Neoplastic lymphocytes may show a loss of markers expressed by their normal counterparts under physiological conditions. Thus the lack of expression of CXCL-13 and CD10 as markers in our case could argue for the neoplastic nature of the PD-1 positive lymphoid cells. We hypothesize that this 
CD4/CD8 double negative unusual variant of MF may derive from neoplastic follicular $\mathrm{T}$ helper cells.

The CD4/CD8 double negative phenotype in MF appears to have no prognostic significance, as so far reported cases showed an indolent course. (3) This is important as the differential diagnosis includes a heterogeneous group of other CTCL with CD4/CD8 double negative phenotype characterized by an aggressive clinical course. (13) Based on the clinical, histological and phenotypic findings, cutaneous gamma/delta lymphoma, peripheral T-cell lymphoma, not otherwise specified (NOS), and infiltrates of angioimmunoblastic T-cell lymphoma could be excluded as differential diagnoses in our patient. The absence of eosinophilic granulocytes, the negative patch test, the phenotype of lymphocytes as well as the detection of clonal T-cells argue against lymphomatoid contact dermatitis.

Although our observation is limited to a single case, it may give insight into the histogenesis of this MF variant and indicate the direction for future studies in the field. The findings will also be of therapeutic significance since PD-1 may serve as an interesting target for therapeutic intervention. (27)

\section{References}

1. Kazakov DV, Burg G, Kempf W. Clinicopathological spectrum of mycosis fungoides. J Eur Acad Dermatol Venereol 2004;18:397-415.

2. Kempf W, Sander CA. Classification of cutaneous lymphomas - an update. Histopathology 2011;56:57-70.

3. Hodak E, David M, Maron L, et al. CD4/CD8 double-negative epidermotropic cutaneous T-cell lymphoma: an immunohistochemical variant of mycosis fungoides. J Am Acad Dermatol 2006;55:276-84.

4. $\quad$ Riley JL. PD-1 signaling in primary T cells. Immunol Rev 2009;229:114-25.

5. Chtanova T, Tangye SG, Newton R, et al. T follicular helper cells express a distinctive transcriptional profile, reflecting their role as non-Th1/Th2 effector cells that provide help for B cells. J Immunol 2004;173:68-78.

6. Rodriguez Pinilla SM, Roncador G, Rodriguez-Peralto JL, et al. Primary cutaneous CD4+ small/medium-sized pleomorphic T-cell lymphoma expresses follicular T-cell markers. Am J Surg Pathol 2009;33:81-90.

7. de Leval L, Rickman DS, Thielen C, et al. The gene expression profile of nodal peripheral T-cell lymphoma demonstrates a molecular link between angioimmunoblastic Tcell lymphoma (AITL) and follicular helper T (TFH) cells. Blood 2007;109:4952-63.

8. Roncador G, Garcia Verdes-Montenegro JF, Tedoldi S, et al. Expression of two markers of germinal center T cells (SAP and PD-1) in angioimmunoblastic T-cell lymphoma. Haematologica 2007;92:1059-66. 
9. Kneba M, Bolz I, Linke B, et al. Characterization of clone-specific rearrangement Tcell receptor gamma-chain genes in lymphomas and leukemias by the polymerase chain reaction and DNA sequencing. Blood 1994;84:574-81.

10. Wood GS, Weiss LM, Hu CH, et al. T-cell antigen deficiencies and clonal rearrangements of $\mathrm{T}$-cell receptor genes in pagetoid reticulosis (Woringer-Kolopp disease). $\mathrm{N}$ Engl J Med 1988;318:164-7.

11. Mielke V, Wolff HH, Winzer M, et al. Localized and disseminated pagetoid reticulosis. Diagnostic immunophenotypical findings. Arch Dermatol 1989;125:402-6.

12. Toro JR, Beaty M, Sorbara L, et al. gamma delta T-cell lymphoma of the skin: a clinical, microscopic, and molecular study. Arch Dermatol 2000;136:1024-32.

13. Jones D, Vega F, Sarris AH, et al. CD4-CD8-"Double-negative" cutaneous T-cell lymphomas share common histologic features and an aggressive clinical course. Am J Surg Pathol 2002;26:225-31.

14. Shimauchi T, Kabashima K, Nakashima D, et al. Augmented expression of programmed death-1 in both neoplastic and non-neoplastic CD4+ T-cells in adult T-cell leukemia/lymphoma. Int J Cancer 2007;121:2585-90.

15. Mourtzinos N, Puri PK, Wang G, et al. CD4/CD8 double negative pagetoid reticulosis: a case report and literature review. J Cutan Pathol 2009;37:491-6.

16. Ralfkiaer E, Wollf-Sneedorff A, Thomsen K, et al. Immunophenotypic studies in cutaneous T-cell lymphomas: clinical implications. Br J Dermatol 1993;129:655-9.

17. Fierro MT, Novelli M, Savoia P, et al. CD45RA+ immunophenotype in mycosis fungoides: clinical, histological and immunophenotypical features in 22 patients. J Cutan Pathol 2001;28:356-62.

18. Ralfkiaer E. Controversies and discussion on early diagnosis of cutaneous T-cell lymphoma. Phenotyping. Dermatol Clin 1994;12:329-34.

19. Massone C, Crisman G, Kerl H, et al. The prognosis of early mycosis fungoides is not influenced by phenotype and T-cell clonality. Br J Dermatol 2008;159:881-6.

20. Edinger JT, Clark BZ, Pucevich BE, et al. CD30 expression and proliferative fraction in nontransformed mycosis fungoides. Am J Surg Pathol 2009;33:1860-8.

21. Kim EJ, Lin J, Junkins-Hopkins JM, et al. Mycosis fungoides and sezary syndrome: an update. Curr Oncol Rep 2006;8:376-86.

22. Wada DA, Wilcox RA, Harrington SM, et al. Programmed death 1 is expressed in cutaneous infiltrates of mycosis fungoides and Sezary syndrome. Am J Hematol 2011;86:3257.

23. Cetinozman F, Jansen PM, Willemze R. Expression of Programmed Death-1 in Primary Cutaneous CD4-Positive Small/Medium-Sized Pleomorphic T-Cell Lymphoma, Cutaneous Pseudo-T-Cell Lymphoma, and Other Types of Cutaneous T-Cell Lymphoma. Am J Surg Pathol 2012;36:109-16.

24. Kantekure K, Yang Y, Raghunath P, et al. Expression patterns of the immunosuppressive proteins PD-1/CD279 and PD-L1/CD274 at different stages of cutaneous T-cell lymphoma/mycosis fungoides. Am J Dermatopathol 2012;34:126-8.

25. Francisco LM, Sage PT, Sharpe AH. The PD-1 pathway in tolerance and autoimmunity. Immunol Rev 2010;236:219-42.

26. Xerri L, Chetaille B, Serriari N, et al. Programmed death 1 is a marker of angioimmunoblastic T-cell lymphoma and B-cell small lymphocytic lymphoma/chronic lymphocytic leukemia. Hum Pathol 2008;39:1050-8.

27. Sakthivel P, Gereke M, Bruder D. Therapeutic Intervention in Cancer and Chronic Viral Infections: Antibody Mediated Manipulation of PD-1/PD-L1 Interaction. Rev Recent Clin Trials 2012;7:10-23.

28. Kazakov DV, Belousova IE, Kacerovska D, et al. Hyperplasia of hair follicles and other adnexal structures in cutaneous lymphoproliferative disorders: a study of 53 cases, 
including so-called pseudolymphomatous folliculitis and overt lymphomas. Am J Surg Pathol 2008;32:1468-78. 


\section{Figure legends:}

Figure 1:

Annular and hypopigmented patches on the left lower leg.

Figure 2:

Epidermis infiltrated by small lymphocytes with chromatin dense nuclei. H\&E, original magnification, $100 \mathrm{X}$

Figure 3: Intraepidermal lymphocytes show nuclear atypia. H\&E, original magnification, $200 \mathrm{X}$

Figure 4:

Both intraepidermal and intradermal lymphocytes express CD3, Immunohistochemistry, original magnification, $100 \mathrm{X}$

Figure 5:

A. Intraepidermal and intradermal lymphocytes express beta-F1. B. Lack of expression of CD4 by intraepidermal lymphocytes. C. Intraepidermal lymphocytes are negative for CD8. D. Intraepidermal lymphocytes express PD-1. (Immunohistochemistry, original magnification, 100X A-D) 
Figure 1
Click here to download high resolution image

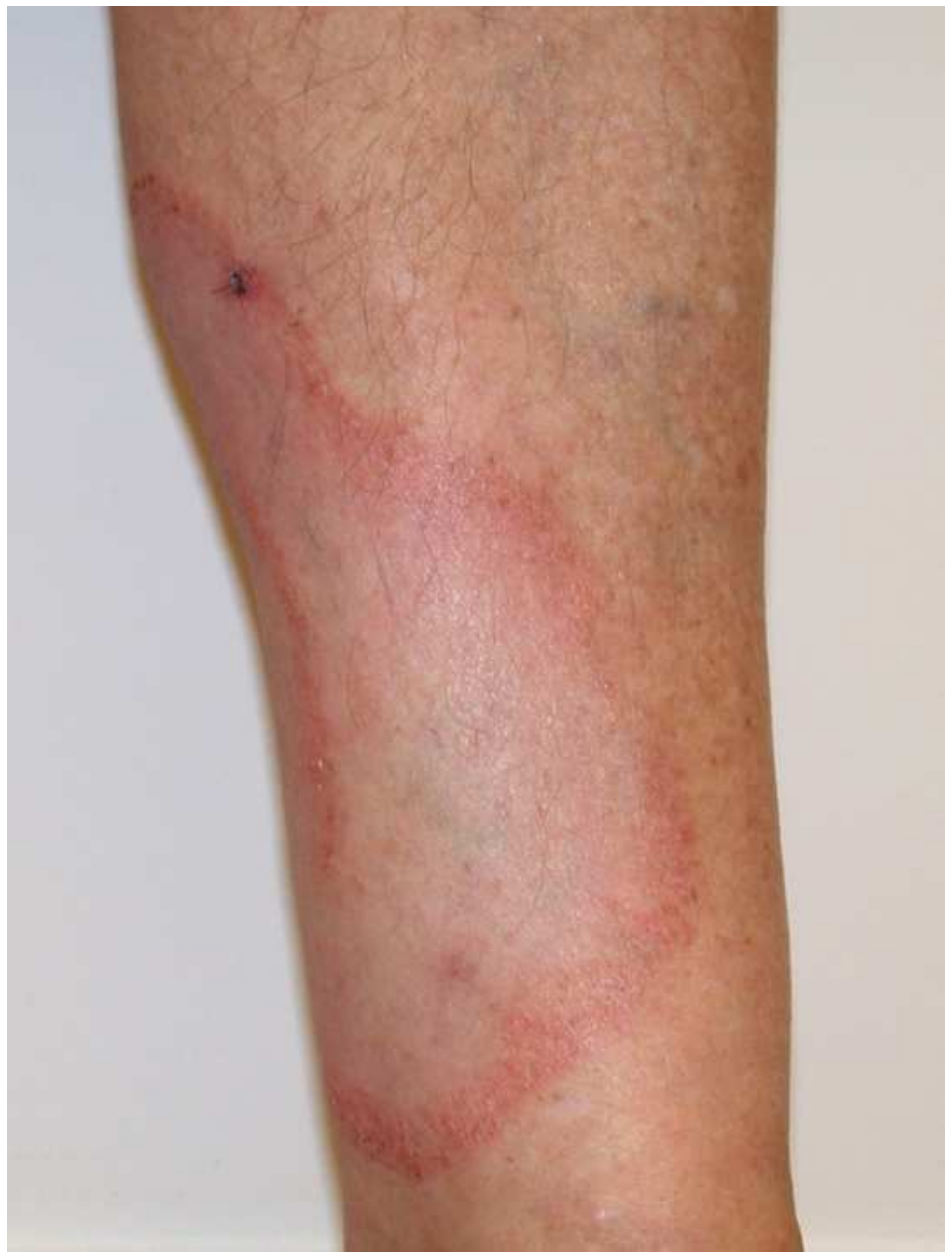




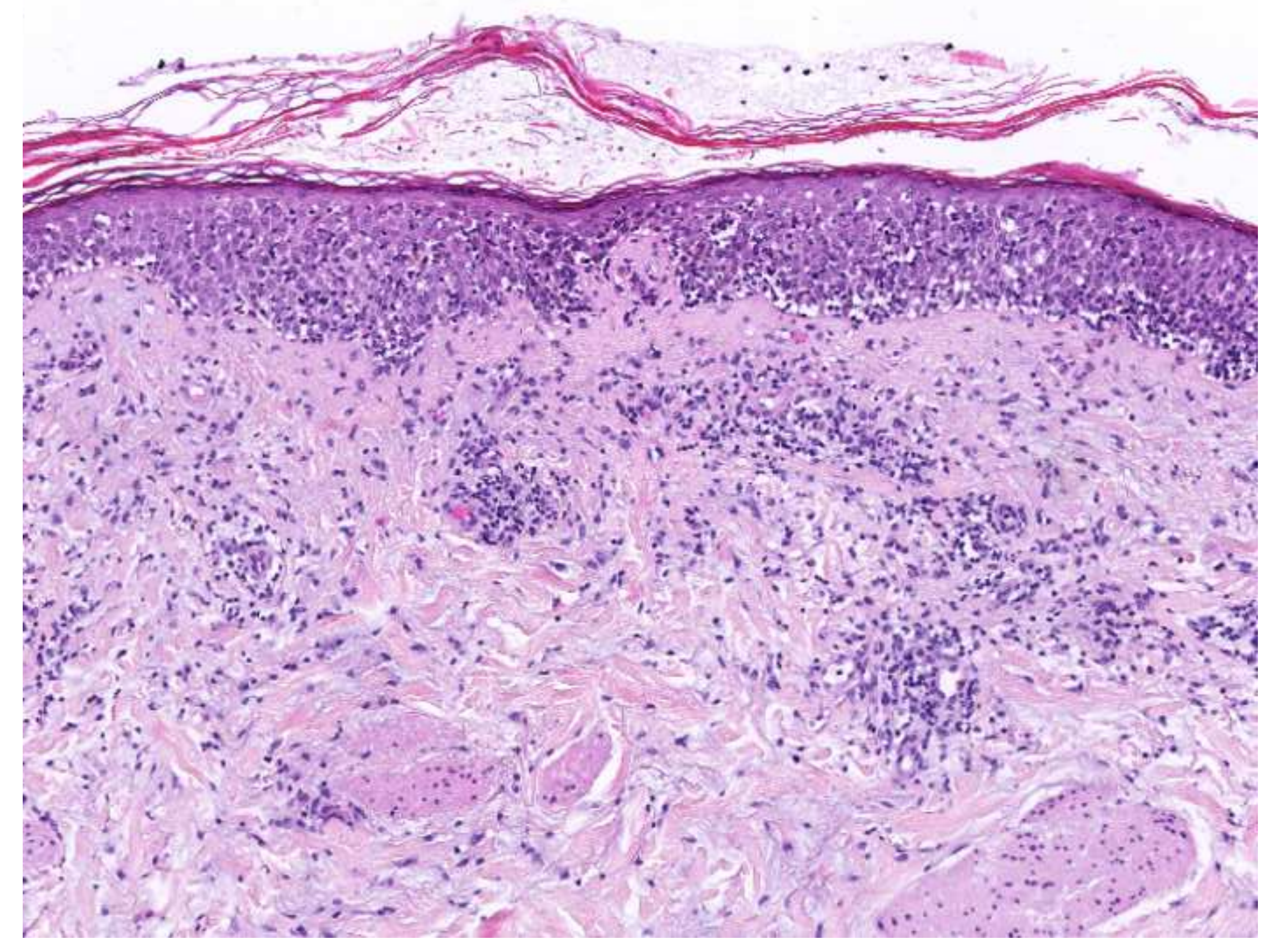


Click here to download high resolution image

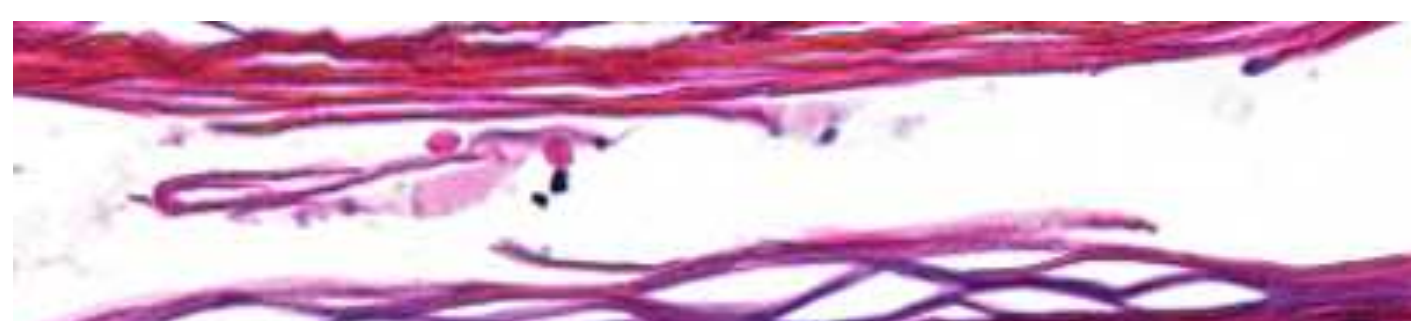

os

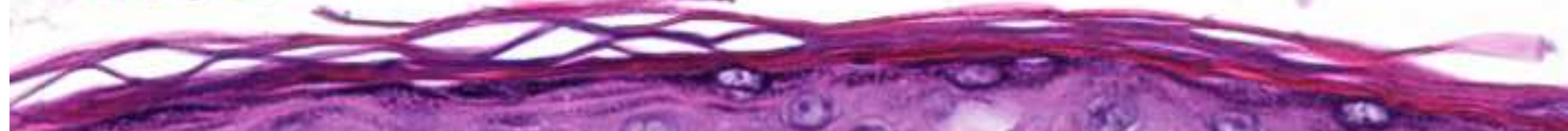

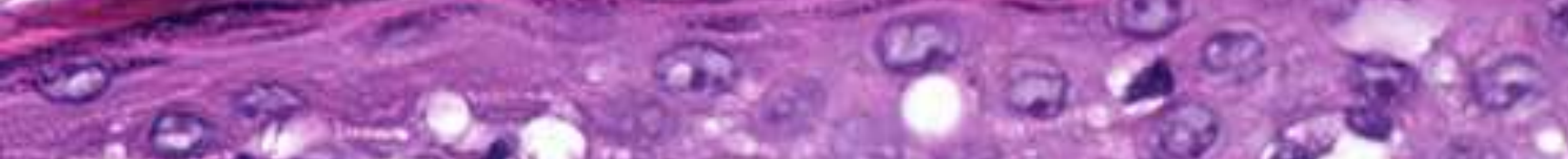

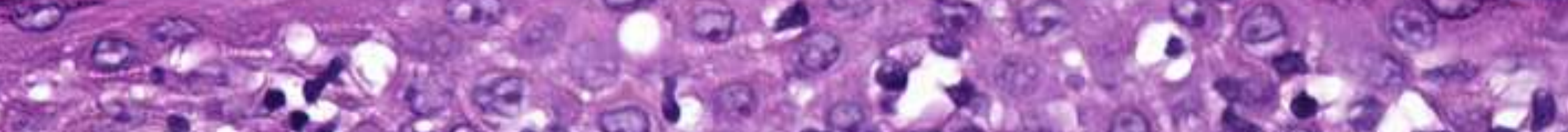

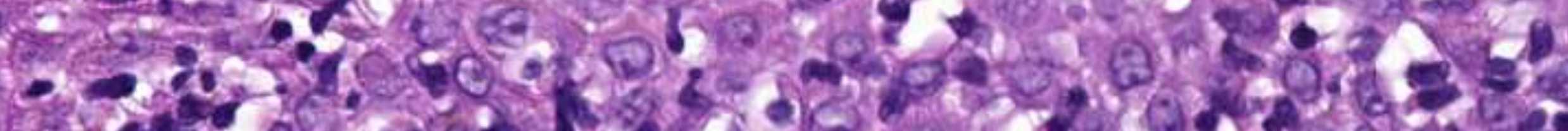

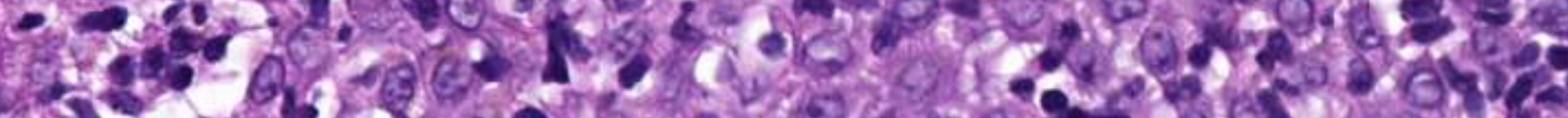

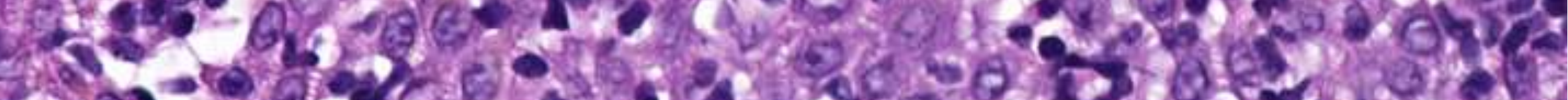

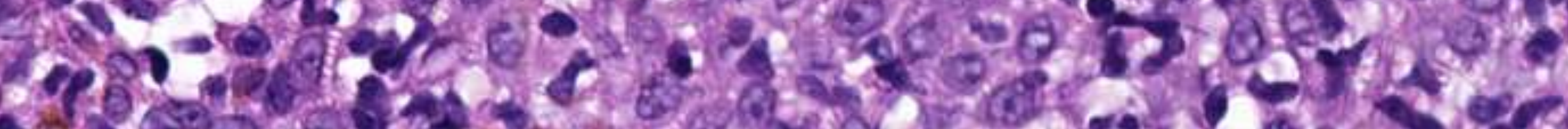

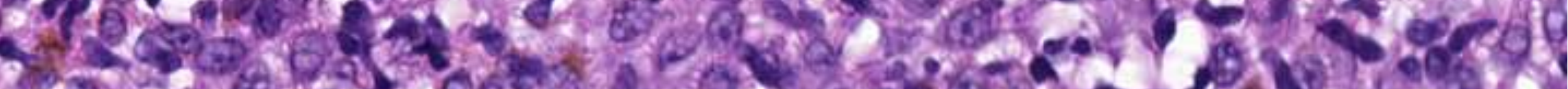

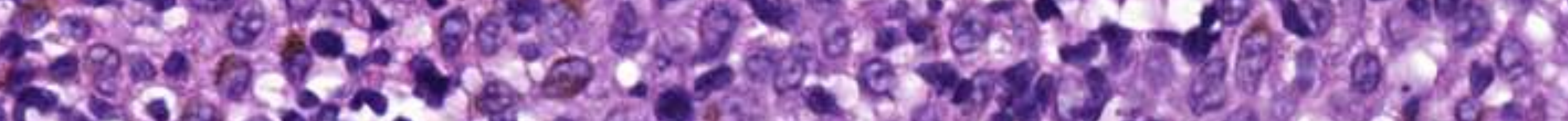

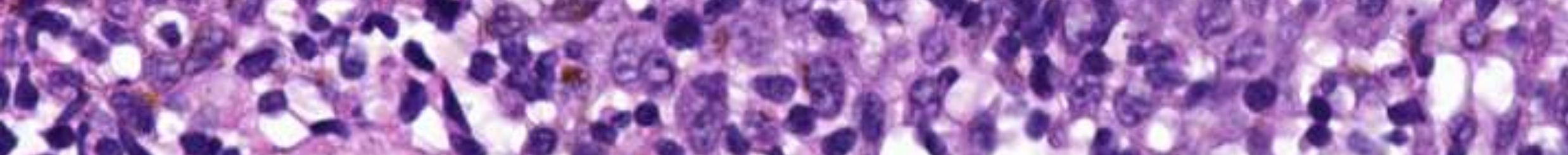

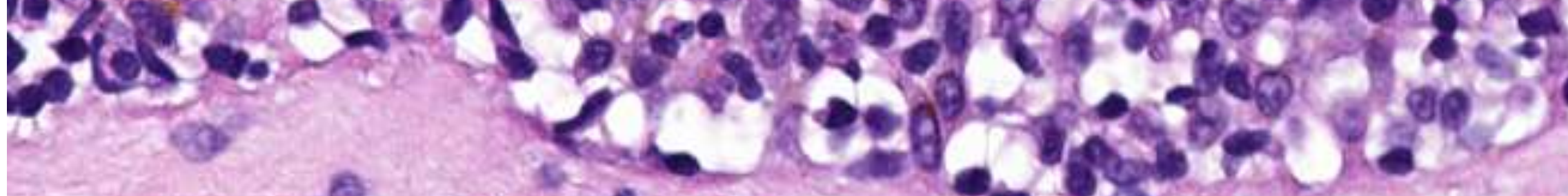

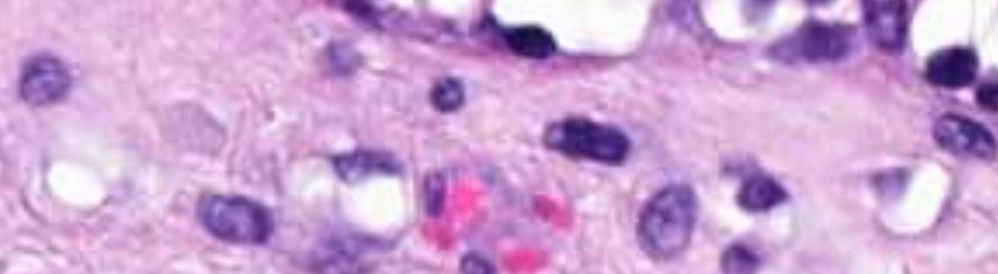

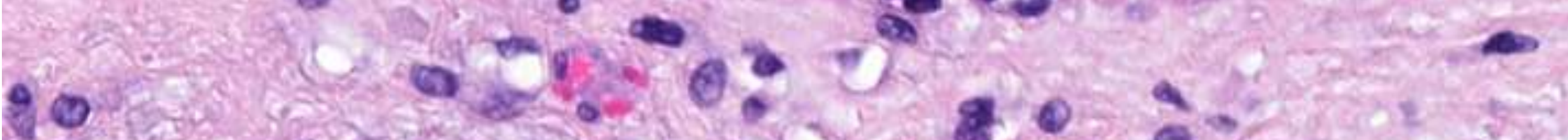

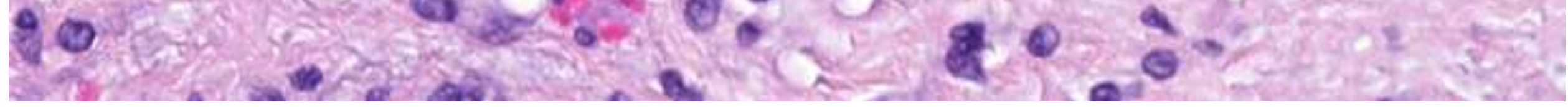



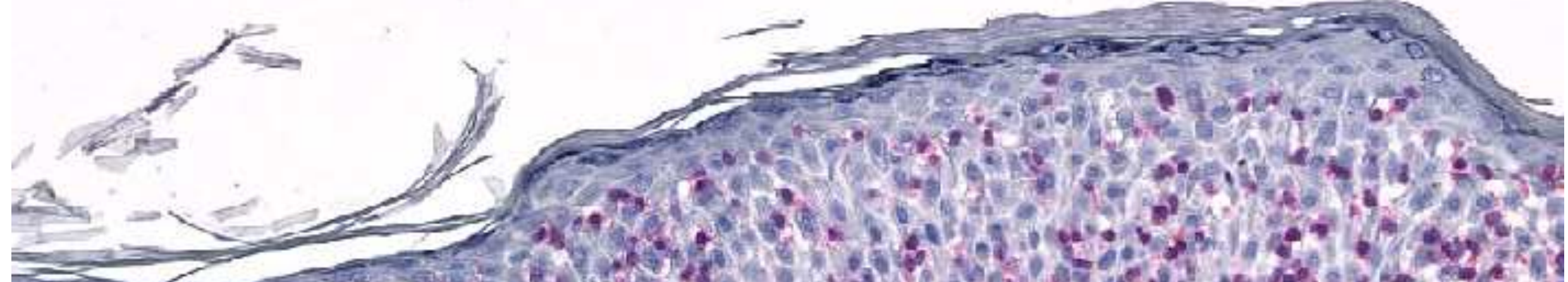
3
5

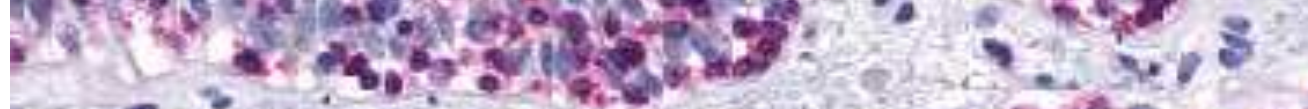

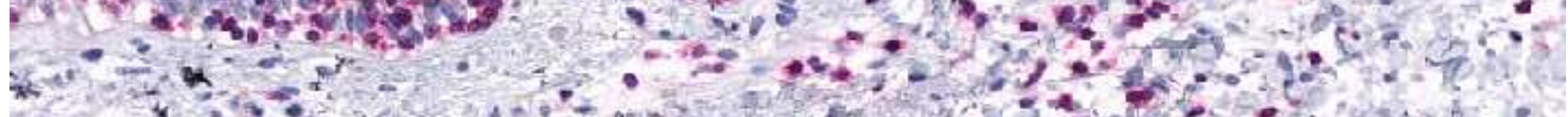

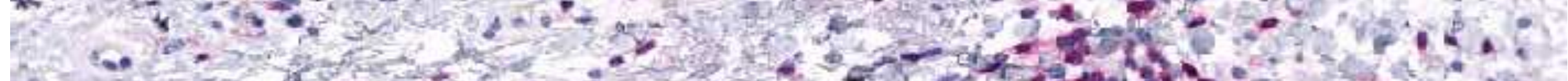

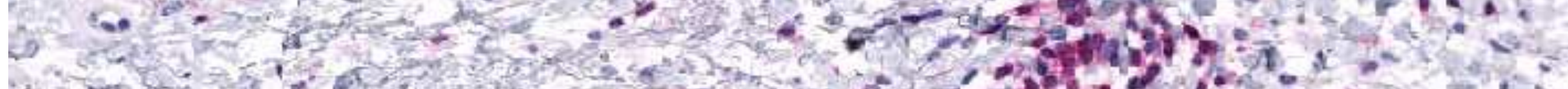

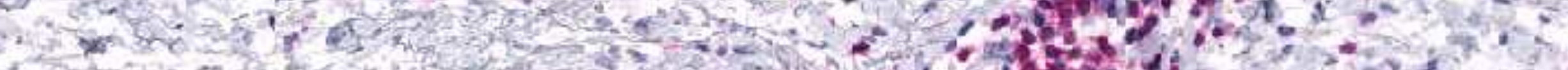

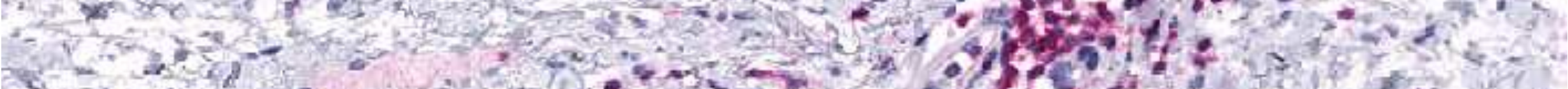

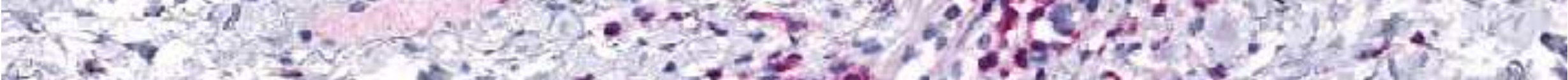

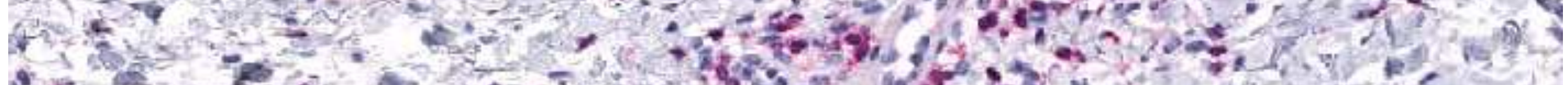

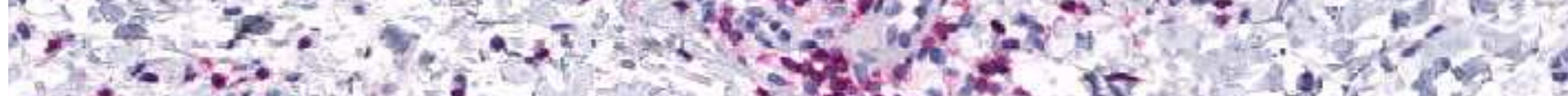

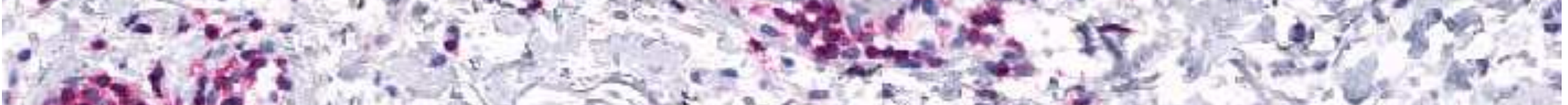

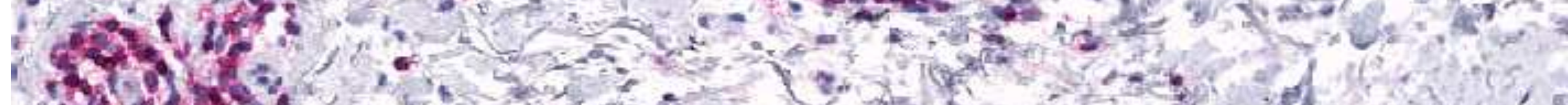

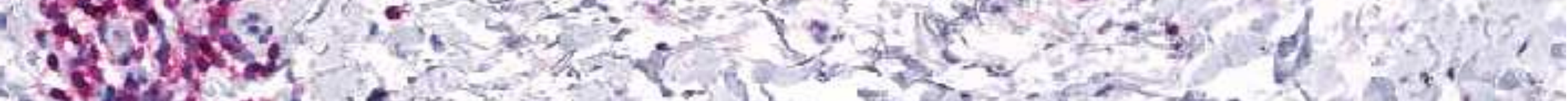

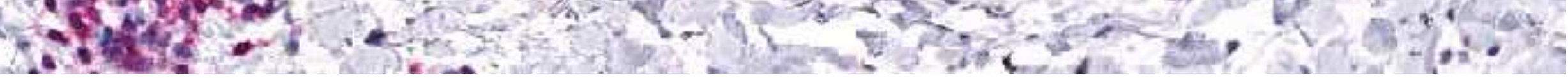




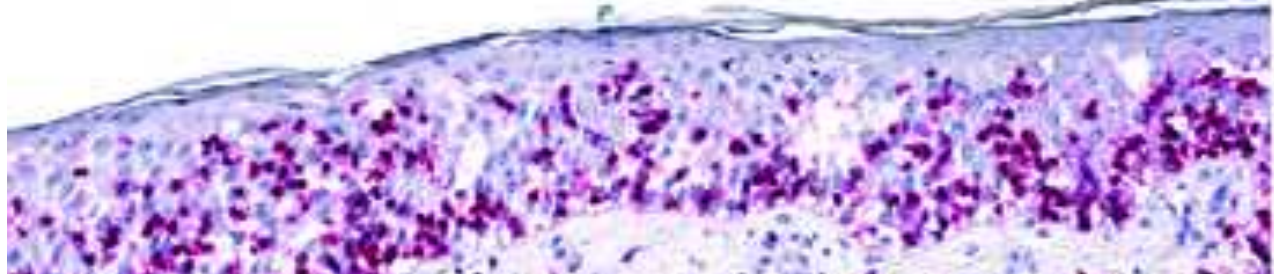

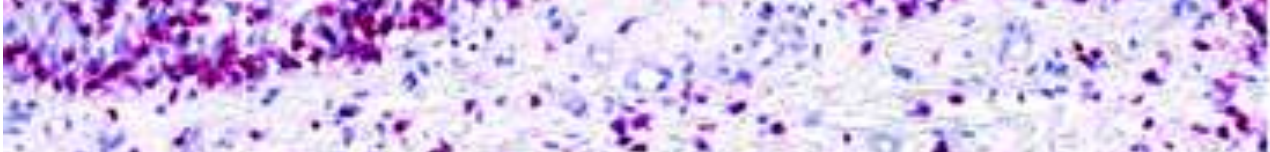

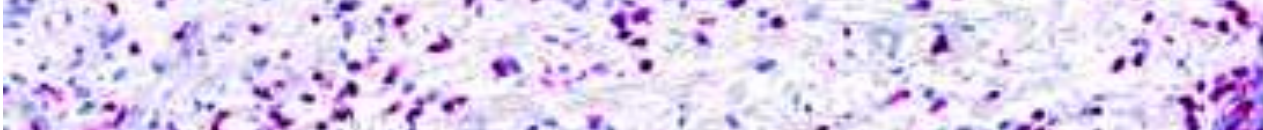

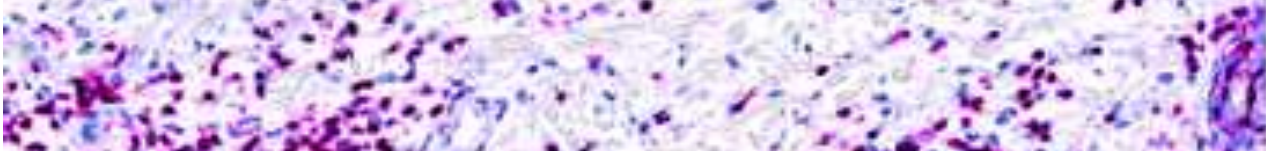

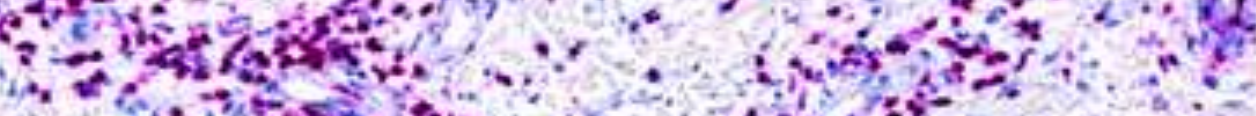

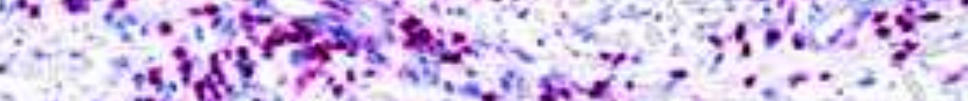

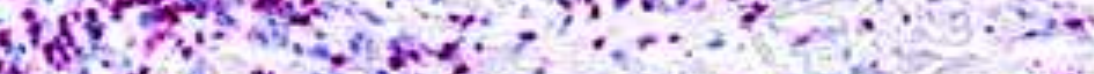

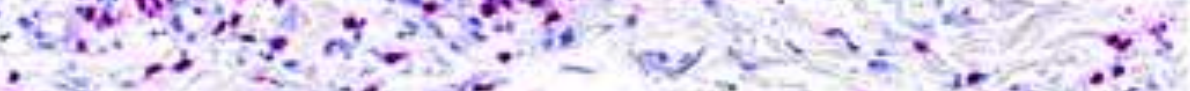
A $-a+n+\ldots+\cdots$

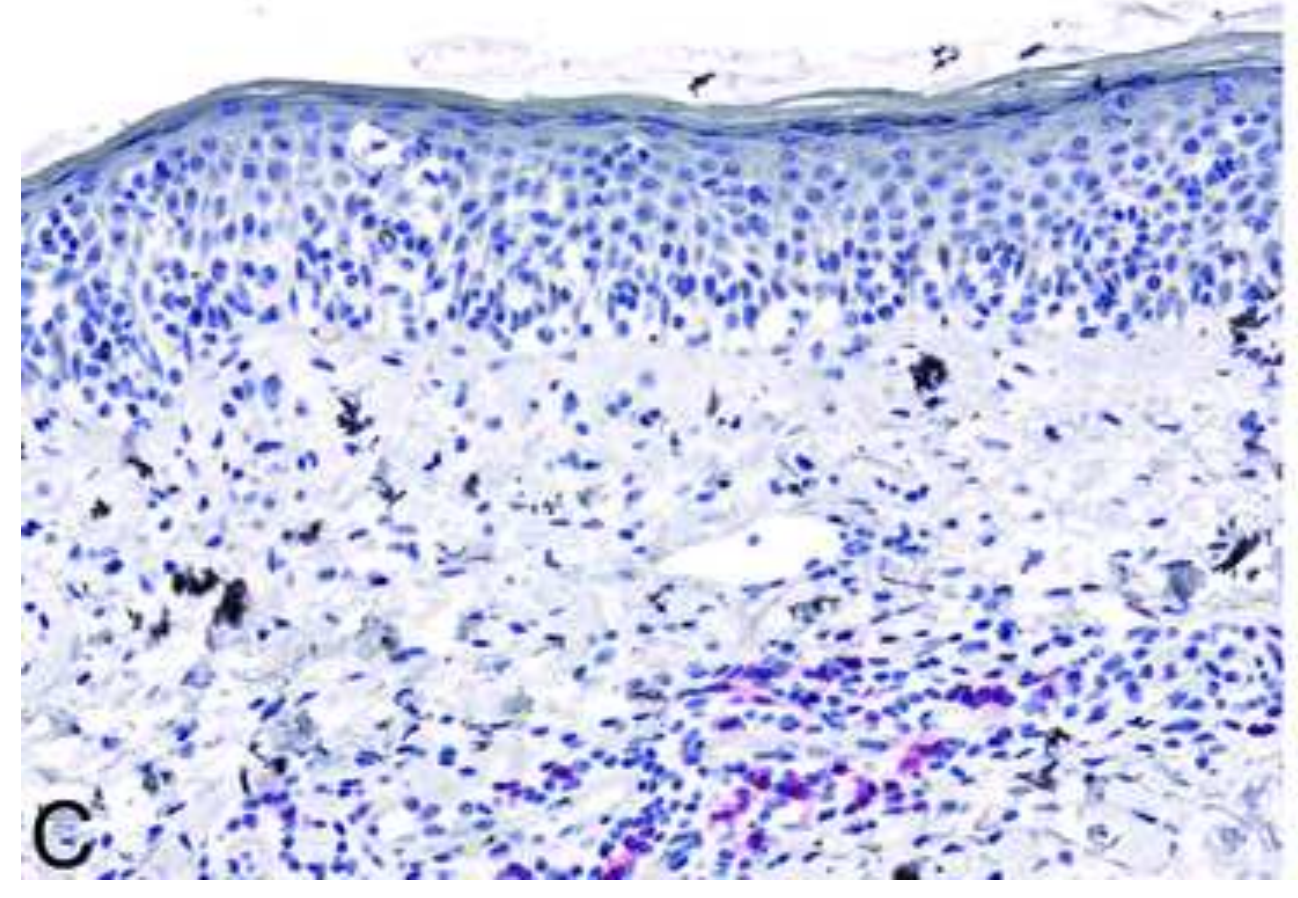
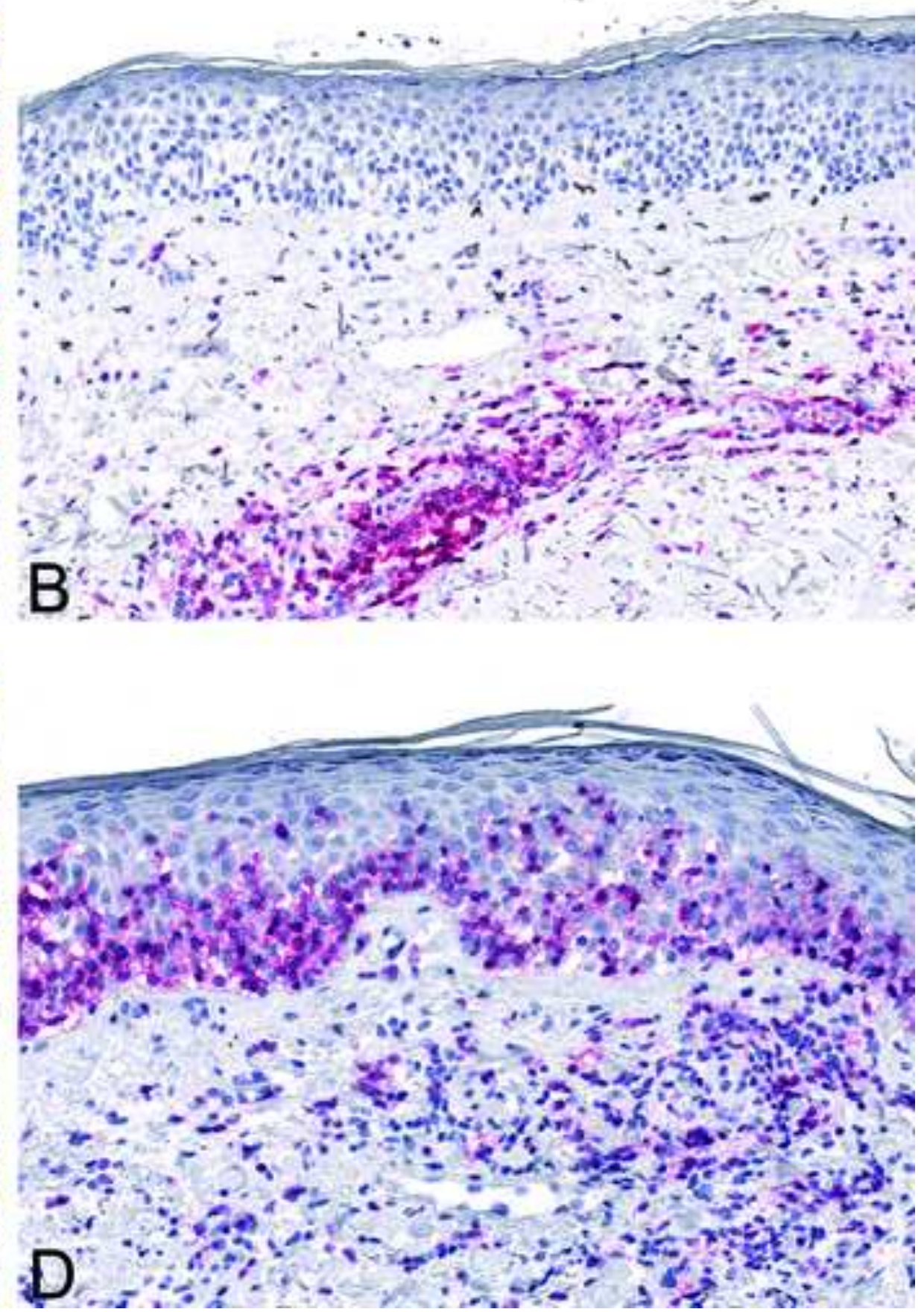


\title{
Cover letter R1 AJD-D-12-00002
}

\author{
Dear Dr. Sangüeza, dear Omar
}

Enclosed please find the revised manuscript " CD4/CD8 double negative mycosis fungoides with PD-1 (CD279) expression - a disease of follicular helper T cells?" (AJD-D-12-00002). We are very grateful for your comments and the comments of the reviewers. Enclosed please find the point-by-point answers to their comments. The corresponding changes in the manuscript has been highlighted by red.

We hope that the revised manuscripts fulfills the requirements and very high standard for publication in the Journal. We very much appreciate your evaluation of our manuscript.

Yours sincerely,

Werner Kempf

Point-by-point answers to the reviewer's comments

Reviewer \#1: This is an intriguing report of a case of mycosis fungoides with an unusual immunophenotype, drawing attention to the potential expression of PD-1 in such cases.

(1) Abstract last sentence: "This is the first report of PD-1 expression in a CD4/CD8 double negative MF." This statement immediately led me to question how often PD-1 is expressed in otherwise ordinary MF. The most recent issue of the American Journal of Surgical Pathology addresses this very question, and likely came out in print after the current paper was submitted. In the AJSP report, 2 of 21 cases of MF showed PD-1 expression, with expression of CXCL13 and bcl6, and with a CD4+ phenotype. Additionally according to Reference 23 in that journal (referring to Am J Hematol 2011;86:325-7) a full 50\% of otherwise typical MF express PD-1. Therefore, its expression in this double negative example may not be so extraordinary, albeit interesting. Since these reports just came out, perhaps a brief mention should be incorporated in the current case report?

Reply: We very much appreciate this comment. In fact, both papers mentioned by the reviewer were discussed and cited in the original version (refs 22 and 23 in the revised version). As seen from these papers, the data on PD-1 in MF are controversial. Whereas the study Cetinötzman et al published in Am J Surg Pathol found expression of PD-1 in only 2 out of $21 \mathrm{MF}$ cases, the other study by Wada et al. reported PD-1 expression in 15 out of 30 MF cases (50\%). There is an additional study just published in the February issue of the Journal (Am J Dermatopathol 2012 Feb;34(1):126-8) after submission of our manuscript. Kantekure et al. described PD-1 positive T-cells was detected in all 9 patch and plaque cases; in 7 of the 9 cases, more than $25 \%$ of the atypical lymphocytes expressed PD-1. These differences may be due to different antibodies and immunohistochemical protocols as well as due to different cut-off levels for positivity. In only a small subset, more than $50 \%$ of cells expressed PD-1. In our case, all intraepidermal tumor cells were positive. We added this point to the discussion including the results of above mentioned studies and the corresponding references (ref 24).

(2) Why did the authors add PD-1 staining to their profile of this double negative MF? The clinical features seem to fit MF despite absence of CD4 or CD8. I might not have thought to do this stain, and wonder what triggered the idea.

Reply: We are currently performing studies on PD-1, FOXP3 as well as other T-cell markers in various CTCL. Due to the very unusual phenotype of our case, we hypothesized that these cells may represent a neoplastic counterpart of one of the above mentioned T-cell subsets and were positively suprised to find expression of PD-1 by all the CD4 CD8 double negative tumor cells. 
(3) Case report: Toward the end of the case report, the authors mention "a relapse was observed." Please clarify, do you mean at the same site?

Reply: The relapse occurred at the same site (left lower leg). This point has been added to the section Case report in the revised version.

(4) Figures are crisp. For some reason Figure 2 is blurry on the computer screen, but when the high-resolution image was downloaded, it looked fine.

Reply: We are grateful for this comment. We checked figure 2 again and did not find it nonpixeled. The figure has a $300 \mathrm{dpi}$ resolution.

(5) Figure 5 is impressive, we have trouble getting such a good result from beta F1. Also interesting the authors stained with the (new?) antibodies to gamma delta T cells.

Reply: We stained for beta F1 and TCR delta 1 which showed reactivity of almost all CD4 CD8 double negative cells for beta F1, but no expression of TCR delta 1. The absence of TCR delta 1 expression has been added to the results in the revised manuscript. Whereas betaF1 gives stable and reproducible staining results, the new antibody against the gamm/delta T-cell receptor (clone 1.302) is challenging. The clone/diluation/source are indicated in the manusrcipt and we will be happy to provide more information if needed.

(6) Immunohistochemical features:

There may be a word missing in the sentence: "The lymphocytes located in the epidermis, CD45RO, whereas the dermal lymphocytes expressed CD45RO." Do you mean the intraepidermal cells were negative for CD45RO?

Reply: We apologize for this incomplete sentence. As suggested by the reviewer, the corrected sentence is: "'The lymphocytes located in the epidermis were negative for CD45RO, whereas the dermal lymphocytes expressed CD45RO."

(7) Discussion page 6 middle: "PD-1 is expressed on activated T cells and B cells." Is expression restricted to CD4 positive T cells? Is it ever seen on CD8 positive cells? When? Is it reported in other instances of CD4/CD8 negative T cells?

Reply: To the best of our knowledge, PD-1 expression has previously not been reported in CD4 CD8 double negative T-cells. A very recent publication (Baitsch et al. PLoS One. 2012;7(2):e30852. Epub 2012 Feb 8) reported expression of PD-1 in CD8-positive T-cells.

Discussion last paragraph: The authors cite a differential diagnosis of cutaneous gamma/delta lymphoma, peripheral T cell lymphoma, and angioimmunoblastic lymphoma. Should another be added to this list, small/medium pleomorphic T cell lymphoma? Does the absence of CD4 expression preclude this? Perhaps a word of clarification here.

Reply: We did not add small/medium pleomorphic $T$ cell lymphoma to the list, since this entity shows absence or only very subtle and focal epiderotropism of lymphocytes, whereas our case was charactreized by prominent epidermotropism. In addition, the tumor cells in small/medium pleomorphic T cell lymphoma express CD4 which was not expressed in the case we report. Due to these two aspects, we did not add small/medium pleomorphic $T$ cell lymphoma to the list of differential diagnoses.

\section{Reviewer \#2:}

(1) The hypothesis proposed by the authors that PD-1 expression probably implies a 
follicular TH (FTH) cell population is flawed. By definition FT "helper cells" are CD4 positive and for the most part bcl6, CXCL-13 and other markers like CD200 should also be expressed.

Reply: The PD-1 positive cells in our case are neoplastic cells. In neoplastic cells a marker loss is often found and may even argue for the neoplastic nature of the PD-1 cells. The PD-1 positive cells in our case partially expressed bcl-6 and CXCL-13 (30\% and $10 \%$, respectively) of the intraepidermal CD4 CD8 double negative cells indicating that the PD-1 positive tumor cells partially retained the phenotype of their physiological or normal counterpart.

(2) In my opinion, based on the localized presentation of the lesions to the lower extremities with illustrations showing a pagetoid pattern with double negative expression, the most accurate diagnosis should be pagetoid reticulosis which often shows a distinct intraepidermal phenotype with CD8+ or double negative phenotype.

Reply: Since the term pagetoid reticulosis according to the current lymphoma classifications is restricted to a unilesional form of MF, we did not employ this term in our patient who had two separate lesions on the left lower leg.

(3) As the authors mentioned, PD-1 is an activation marker and it's also often expressed in subsets of CTCL, especially Sezary syndrome, not necessarily associated with a FTH phenotype. Intraepidermal expression of PD-1 cells probably reflects an activated phenotype, albeit CD30 negative. CD25 could also be checked as an alternative. Since viral infections tend to express PD-1, EBER or LNP-1 should be considered.

Reply: Remarkably, less than $10 \%$ of the PD-1 positive showed reactivity for CXCL-13 and bcl- 6 was expressed by $30 \%$ of the intraepidermal PD-1 positive lymphocytes. This lack of additional markers, i.e. antigen loss, is a common phenomenon in T-cell lymphoma. This observation may support the hypothesis that the CD4 CD8 double negative tumor cells in this MF variant are the (neoplastic) counterpart of PD-1 cells characterized by antigen loss for CXCL-13 and bcl-6 due their neoplastic nature. Despite the tumor cells did not express CD25., the partial expression of MUM-1 may indicate that the tumor cells in our case carry features of activated T-cells. These informations were added to the revised manuscript. In situ hybridization for EBV (EBER) was negative as mentioned in the text.

(4) In the discussion section the phrase "The lack of expression of CXCL-13 and CD10?may be suggestive of FTH cells" is a bit confusing since both of these markers should be expressed in FTH cells.

Reply: Please see comment to point 1.

(5) CD7 expression is also not typical of FTH, AITL is mostly CD7 negative.

Reply. We agree with this comment. We examined CD7 since in MF the intraepidermal cells often exhibit loss of CD7.

(6) Hypothyreosis is an unfamiliar term in the US, suggest hypothyroidism instead.

Reply: The term was corrected in the revised manuscript as suggested by the reviewer.

Reviewer \#3:

This is an interesting observation on a patient with mycosis fungoides (MF). 
1) There should be less emphasys on pathogenetic and therapeutic possibilities related to PD-1 expression, as this is a single case report. A recent publication showed that PD-1 is not commonly expressed in early MF (ref. 22 in the present manuscript).

Reply: In regard to the development of personalized targeted therapy in oncology, the expression of PD-1 and other markers may be of therapeutic relevance even if only a subset of cases shows expression of such markers. Moreover, very recent publications show controversial data on the prevalence of PD-1 expression in MF (see comment 1 to reviewer 1). Therefore, we would like to mention the potential link of PD-1 as a target for therapeutic interventions.

2) PD-1 may be expressed also by cells other than follicular T-helper lymphocytes.

Reply: A few other lymphocytic subsets such as CD8 positive T-cells have been reported to express PD1 (please see also point 7 in the comments of reviewer no. 1).

3) There are more than 32 cases of CD4-/CD8- MF in the literature; a manuscript on large numbers of MF with phenotypic features should be cited and added to the reference list $(\mathrm{Br} J$ Dermatol 2008;159:881-886). There are several other cases in isolated reports - it should be more clearly stated that the suggestion that this is a "geographical" variant is devoid of any support.

Reply: We are grateful for this information. The reference in which 2 double negative cases of mycosis fungoides were inlcuded ( $\mathrm{Br} \mathrm{J}$ Dermatol 2008;159:881-886) has now been cited in the revised version of the manuscript (Ref 19). Following the statments of the reviewer that "There are more than 32 cases of CD4-/CD8- MF in the literature and There are several other cases in isolated reports ", we have also checked once again the literature and found only one additional reference - Ralfkiaer E 1994. This paper has now been included in the revsied manuscript.

The reviewer is right in indicating that the suggestion the disease in question is not a geographical MF variant and this is exactly what we are saying. However, when Hodak et al made this suggestion, it was quite logical given their data.

4) the pictures are of very good quality; however, figure 4 can be omitted; figures 5-8 should be put in a panel.

Reply: Figure 4 demonstrates expression of the pan T-cell marker CD3 by the tumor cells. Thus we would prefer to keep this fugure. We followed the suggestion of the reviewer to put figures 5-8 into a composite panel. 
CD4/CD8 double negative mycosis fungoides with PD-1 (CD279) expression - a disease of follicular helper $\mathbf{T}$ cells?

\section{Authors:}

Werner Kempf, MD (1, 2), Dmitry V. Kazakov, MD, PhD (3), Claudio Cipolat (4), Heinz Kutzner, MD (5), Giovanna Roncador, MD, PhD (6), Dario Tomasini, MD (7)

\section{Institutions:}

(1) Kempf und Pfaltz, Histologische Diagnostik, Zürich, Switzerland

(2) Department of Dermatology, University Hospital, Zürich, Switzerland,

(3) Department of Pathology, Faculty of Medicine in Pilsen, Charles University in Prague, Czech Republic

(4) Dermatology Practice, Dübendorf, Switzerland

(5) Dermatopathologie Friedrichshafen Bodensee, Friedrichshafen, Germany;

(6) Centro Nacional de Investigaciones Oncologicas, Madrid, Spain

(7) Department of Dermatology, Hospital of Busto Arsizio, Busto Arsizio, Italy.

Running title: $\quad$ PD-1 positive CD4/CD8 double negative mycosis fungoides

\section{Corresponding author:}

Werner Kempf, MD

Kempf und Pfaltz

Histologische Diagnostik

Seminarstrasse 1

CH-8042, Zurich

Switzerland

Tel +41-44-2333377

Fax +41-44-2333378

e-mail kempf@kempf-pfaltz.ch 


\begin{abstract}
CD4/CD8 double negative mycosis fungoides (MF) is a rare phenotypic variant of this epidermotropic cutaneous T-cell lymphoma. Clinically, this MF form manifests with unusual appearances such as annular lesions confined to one body region like in our patient in whom the lesions were found on the left lower leg. The cellular origin of CD4/CD8 double negative $\mathrm{MF}$ is unknown. In our case, the intraepidermal CD4/CD8 double negative clonal $\mathrm{T}$ lymphocytes (CD2+, CD4-, CD8-, CD30-, betaF1+) expressed PD-1, but were negative for CXCL-13 and cytotoxic molecules (TIA-1, granzyme B, perforin). Our observation may give insight into the histogenesis of this unique MF variant and may also be of therapeutic significance since PD-1 may serve a target for therapeutic intervention.
\end{abstract}

Key words: mycosis fungoides, cutaneous T-cell lymphoma, CD8, PD-1 


\section{Introduction}

Mycosis fungoides (MF) is the most common primary cutaneous lymphoma and shows a broad clinicopathologic as well as prognostic spectrum. (1), (2). CD4/CD8 double negative MF is a rare phenotypic variant. In a recent series, this double negative phenotype has been found in 18 (12\%) of 140 patients with early stage MF. (3) Unusual clinical presentations including localized, hypopigmented and ichthyosiform have been observed to be overrepresented in that cohort. The authors of the original series discussed issues concerning the origin of CD4-CD8- neoplastic cells in MF as to whether they could represent a malignant counterpart of the normal subpopulation of lymphocytes or derive from antigen-driven $\mathrm{T}$ cells that lost expression of both markers. (3). Herewith we describe a MF patient with this peculiar immunophenotype and demonstrate that the CD4-CD8- in our case expressed the programmed death-1 (PD-1), an inhibitory member of the CD28 family located on chromosome 2q37. (4) PD-1 is expressed by a specific subset of $\mathrm{T}$ cells that are normally present in germinal centers with a helper function for follicular B cells (follicular helper $\mathrm{T}$ cells, $\mathrm{T}_{\mathrm{FH}}$ cells). These cells are characterized by a unique gene expression profile distinct from those of other naive, memory, and effector T helper subsets. (5) PD-1 expression is a characteristic feature of primary cutaneous CD4-positive small/medium-sized T-cell lymphoma (CD4+ SMPTL) (6) and in angioimmunoblastic T-cell lymphoma. (7), (8) We report for the first time the expression of PD-1 in CD4/CD8-double negative MF and discuss its significance.

\section{Material and methods}

Biopsy specimens were fixed in $10 \%$ buffered formalin and sections were routinely processed and embedded in paraffin. Serial 4 micrometer-thick sections were cut for hematoxylin and eosin stains as well as immunohistochemical stains. The antibodies used for immunohistochemistry included: CD2 (1:50, Novocastra/Leica-Microsystems, Heerbrugg, Switzerland), CD3 (1:75, Dako, Glostrup, Denmark), CD4 (1:2, Novocastra/LeicaMicrosystems, Heerbrugg, Switzerland), CD7 (1:25, Dako, Glostrup, Denmark), CD8 (1:400, Dako, Glostrup, Denmark), CD10 (1:100; Novocastra/Leica-Microsystems, Heerbrugg, Switzerland), CD20 (1:600, Dako, Glostrup, Denmark), CD30 (1:75; Novocastra/LeicaMicrosystems, Heerbrugg, Switzerland), CD45RO (RTU, Novocastra/Leica-Microsystems, Heerbrugg, Switzerland), CD45RA (1:100; Novocastra/Leica-Microsystems, Heerbrugg, Switzerland), CD56 (RTU, Novocastra/Leica-Microsystems, Heerbrugg, Switzerland), TIA-1 (1:50, Immunotech Marseille, France), beta F1 (1:50, Thermo Scientific, Germany), TCR 
gamma/delta (1:100, Thermo Scientific, Germany), PD-1 (1:10, developed by G. Roncador, MD PhD, Madrid, Spain), CXCL-13 (1:10; R\&D Systems, Abingdon, UK), EBER in situ hybridization (RTU, Novocastra/Leica-Microsystems, Heerbrugg, Switzerland). Appropriate positive controls were included.

\section{Case Report}

A 70-year old woman presented with long-standing erythematous patches on the on the left lower leg (Fig. 1). The lesions had developed 5 years ago as slightly hypopigmented macular lesions. The annular erythematous margin had appeared 6 months before consultation. Family history revealed lymphocytic leukemia in a grandchild of the patient. The patient was treated for hypothyroidism, but otherwise was healthy. Due to accentuated margins and clinical resemblance to a fungal infection, the patient had been treated with topical antimycotics, with no success. Physical examination did not show enlarged lymph nodes. Results of hematologic examination of peripheral blood, serologic findings (LDH) as well as radiologic staging including computer tomography of the chest and abdomen did not reveal abnormalities. Patch testing performed in the phase of complete remission did not show delayed type hypersensitivity to standard allergens. Following histopathological diagnosis, the patient was treated with UVB barrow band $(311 \mathrm{~nm}$ ) (three times per week) over a period of 10 weeks and topical steroids (momentasone furoat cream, once per day for 5 days per week) for 5 weeks. This treatment resulted in complete remission. One month after the treatment has been finished, a local relapse with a solitary slightly infiltrated annular lesion on the left lower leg was observed with partially responded to topical steroids (halometasone cream) applied over a period of three weeks with partial remission. The patient discontinued treatment since she was afraid of side effects of topical steroids and since she was not disturbed by the disease. Stable disease with a persisting solitary annular lesion was observed during follow-up of 8 months.

\section{Histopathological findings}

The epidermis was slightly acanthotic, with variable degree of spongiosis. Discrete parakeratotic cornification was present (Fig. 2). The epidermis was heavily infiltrated by small lymphocytes with chromatin dense nuclei, some of them with irregular nuclear contours (Fig 3). In the upper dermis, the lymphoid infiltrate was mainly arranged around blood vessels, but additionally a focal interstitial component was present. Eosinophilic granulocytes and plasma cells were not found.

\section{Immunohistochemical features}


Both intraepidermal and intradermal lymphocytes expressed CD2, CD3, and beta-F1, but intraepidermal lymphocytes were negative for CD4 and CD8 (Figs 4, 5). Approximately 70\% of the intrapeidermal lymphocytes expressed CD7. More than $90 \%$ of the intraepidermal lymphocytes expressed PD-1 and less than 10\% showed reactivity for CXCL-13 (Fig 5). Bcl6 was expressed by $30 \%$ of the intraepidermal lymphocytes. The lymphocytes located in the epidermis were negative for CD45RO, whereas the dermal lymphocytes expressed CD45RO and CD4. CD8 and FOXP3 stained a few dermal lymphocytes, whereas no immunopositivity for the two markers was seen in the epidermal component. CD10, CD20, CD30, CD45RA, CD56 and TIA, perforin and granzyme B were not expressed. MUM1 labeled few lymphocytes both in the epidermal and dermal component. Staining for T-cell receptor (TCR) delta chain and in situ hybridization for EBV (EBER) were negative.

\section{Molecular biological assays}

T-cell receptor (TCR) rearrangement studies were performed using a multiplex polymerase chain reaction (PCR) with denaturing gradient gel electrophoresis as described elsewhere (9) and revealed a monoclonal rearrangement of TCR gamma genes.

\section{Discussion}

The spectrum of CD4/CD8 double negative cutaneous T-cell lymphomas reported in the literature encompasses MF, pagetoid reticulosis, gamma/delta-positive cutaneous T-cell lymphoma, HTLV-1 associated adult T-cell lymphoma/leukemia, and cases which can be classified as cutaneous peripheral T-cell lymphoma, unspecified according to the WHO classification (2008; 4th edition) (10), (11), (12), (13), (14), (15) . Less than 35 cases of CD4/CD8 double negative early MF have been reported since the first description in 1993 by Ralfkiaer and coworkers (16), (17), (3) , (18), (19) Our case supports the observation of Hodak et al that CD4/CD8 double negative MF is often associated with an unusual clinical presentation as in our patient in whom CD4/CD8 double negative MF clinically presented with annular and centrally hypopigmented lesions confined to the left lower leg as one body region also referred to as localized MF. Except for the expression of CD30 in early MF, none of the phenotypic MF variants appears to be of prognostic significance. (20). Due to the fact that cases of $\mathrm{CD} 4 / \mathrm{CD} 8$ double negative $\mathrm{MF}$ had not been recognized prior to their work, Hodak et al considered the possibility that this variant of MF might be unique to the Middle East. (3) Our patient is of Swiss origin. In conjunction with previous reports our observation confirms that $\mathrm{CD} 4 / \mathrm{CD}$ double negative MF occurs also in countries of central/western Europe. (16), (17), (19). 
In contrast to the majority of the previously reported cases of $\mathrm{CD} 4 / \mathrm{CD} 8$ double negative $\mathrm{MF}$ cases, the intraepidermal CD4 and CD8 negative tumor cells in our patient did not express cytotoxic molecules (TIA-1, granzyme B, perforin) indicating that the tumor cells do not belong to cytotoxic T-cells. The classic CD4+ form of MF is considered to represent a neoplasm derived from memory T helper cells. (21) The cellular origin of CD4/CD8 double negative MF, however, is unknown. In our case, the intraepidermal CD4/CD8 double negative clonal lymphocytes expressed PD-1. PD-1 expression in CTCL including MF has little been investigated to date and the results appears controversial. Roncandor et al found PD-1 positivity was found in 4 out of 5 cases (80\%). In contrast, Wada et al detected PD-1 immunoreactivity only 15 of $30 \mathrm{MF}$ cases (50\%). (8), (22) In two most recent articles, Cetinözman et al. reported PD-1 in only a subset of 2 out of 21 MF cases (9\%) (23), whereas Kantekure et al detected PD-1 positive T cells in all 9 patch and plaque MF cases, with 7 of the 9 cases showing more than $25 \%$ of the atypical lymphocytes expressing PD-1. (24) These differences may be due to different antibodies and immunohistochemical protocols well as due to different cut-off levels for positivity. There was no specification as to whether these cases manifested the usual and most common CD4+CD8- phenotype.

Expression of PD-1 characterizes follicular helper $\mathrm{T}$ cells $\left(\mathrm{T}_{\mathrm{FH}}\right)$, which are normally present in germinal centers and possess helper function for B-cells. (4) PD-1 is expressed on activated T cells and B cells. PD-1 is a negative regulator of $\mathrm{T}$ cell activation and proliferation that mediates suppressive action by binding to its ligands PD-L1 and PD-L2. (25) In the context of lymphomas, PD-1 cells have been found to be expressed in nodal angioimmunoblastic T-cell lymphoma and in primary cutaneous lymphomas classified as CD4+SMPTL and identical lesions diagnosed by others as pseudolymphomatous folliculitis or nodular T-cell pseudolymphoma. (7), (26), (6) It can be speculated that CD4/CD8 double negative MF represents a neoplastic counterpart of $\mathrm{T}_{\mathrm{FH}}$ cells. Alternatively, expression of PD-1 may be upregulated as the result of activation of antigen-stimulated T cells with loss of CD4 and CD8 since PD-1 can be expressed on activated T-cells. Remarkably, the PD-1 positive tumor cells in our case did not show expression of CXCL-13 and bcl-6 only in 30\%, whereas tumor cells in cutaneous CD4+ SMPTL express both markers. (6) The lack of expression of CXCL-13 and CD10 as markers expressed by follicular T helper cells under physiological conditions may be suggestive of a possible origin of this unusual variant of MF from neoplastic follicular $\mathrm{T}$ helper cells. 
The CD4/CD8 double negative phenotype in MF appears to have no prognostic significance, as so far reported cases showed an indolent course. (3) This is important as the differential diagnosis includes a heterogeneous group of other CTCL with CD4/CD8 double negative phenotype characterized by an aggressive clinical course. (13) Based on the clinical, histological and phenotypic findings, cutaneous gamma/delta lymphoma, peripheral T-cell lymphoma not otherwise unspecified (NOS), and infiltrates of angioimmunoblastic T-cell lymphoma could be excluded as differential diagnoses in our patient. The absence of eosinophilic granulocytes, the negative patch test, the phenotype of lymphocytes as well as the detection of clonal T-cells argue against lymphomatoid contact dermatitis.

Although our observation is limited to a single case, it may give insight into the histogenesis of this MF variant and indicate the direction for future studies in the field. The findings will also be of therapeutic significance since PD-1 may serve as an interesting target for therapeutic intervention. (25)

\section{References}

1. Kazakov DV, Burg G, Kempf W. Clinicopathological spectrum of mycosis fungoides. J Eur Acad Dermatol Venereol 2004;18:397-415.

2. $\quad$ Kempf W, Sander CA. Classification of cutaneous lymphomas - an update. Histopathology 2011;56:57-70.

3. Hodak E, David M, Maron L, et al. CD4/CD8 double-negative epidermotropic cutaneous T-cell lymphoma: an immunohistochemical variant of mycosis fungoides. J Am Acad Dermatol 2006;55:276-84.

4. Riley JL. PD-1 signaling in primary T cells. Immunol Rev 2009;229:114-25.

5. Chtanova T, Tangye SG, Newton R, et al. T follicular helper cells express a distinctive transcriptional profile, reflecting their role as non-Th1/Th2 effector cells that provide help for B cells. J Immunol 2004;173:68-78.

6. Rodriguez Pinilla SM, Roncador G, Rodriguez-Peralto JL, et al. Primary cutaneous CD4+ small/medium-sized pleomorphic T-cell lymphoma expresses follicular T-cell markers. Am J Surg Pathol 2009;33:81-90.

7. de Leval L, Rickman DS, Thielen C, et al. The gene expression profile of nodal peripheral T-cell lymphoma demonstrates a molecular link between angioimmunoblastic $\mathrm{T}$ cell lymphoma (AITL) and follicular helper T (TFH) cells. Blood 2007;109:4952-63. 8. Roncador G, Garcia Verdes-Montenegro JF, Tedoldi S, et al. Expression of two markers of germinal center T cells (SAP and PD-1) in angioimmunoblastic T-cell lymphoma. Haematologica 2007;92:1059-66.

9. Kneba M, Bolz I, Linke B, et al. Characterization of clone-specific rearrangement Tcell receptor gamma-chain genes in lymphomas and leukemias by the polymerase chain reaction and DNA sequencing. Blood 1994;84:574-81. 
10. Wood GS, Weiss $\mathrm{LM}, \mathrm{Hu} \mathrm{CH}$, et al. T-cell antigen deficiencies and clonal rearrangements of T-cell receptor genes in pagetoid reticulosis (Woringer-Kolopp disease). $\mathrm{N}$ Engl J Med 1988;318:164-7.

11. Mielke V, Wolff HH, Winzer M, et al. Localized and disseminated pagetoid reticulosis. Diagnostic immunophenotypical findings. Arch Dermatol 1989;125:402-6.

12. Toro JR, Beaty M, Sorbara L, et al. gamma delta T-cell lymphoma of the skin: a clinical, microscopic, and molecular study. Arch Dermatol 2000;136:1024-32.

13. Jones D, Vega F, Sarris AH, et al. CD4-CD8-"Double-negative" cutaneous T-cell lymphomas share common histologic features and an aggressive clinical course. Am J Surg Pathol 2002;26:225-31.

14. Shimauchi T, Kabashima K, Nakashima D, et al. Augmented expression of programmed death-1 in both neoplastic and non-neoplastic CD4+ T-cells in adult T-cell leukemia/lymphoma. Int J Cancer 2007;121:2585-90.

15. Mourtzinos N, Puri PK, Wang G, et al. CD4/CD8 double negative pagetoid reticulosis: a case report and literature review. J Cutan Pathol 2009;37:491-6.

16. Ralfkiaer E, Wollf-Sneedorff A, Thomsen K, et al. Immunophenotypic studies in cutaneous T-cell lymphomas: clinical implications. Br J Dermatol 1993;129:655-9.

17. Fierro MT, Novelli M, Savoia P, et al. CD45RA+ immunophenotype in mycosis fungoides: clinical, histological and immunophenotypical features in 22 patients. J Cutan Pathol 2001;28:356-62.

18. Ralfkiaer E. Controversies and discussion on early diagnosis of cutaneous T-cell lymphoma. Phenotyping. Dermatol Clin 1994;12:329-34.

19. Massone $\mathrm{C}$, Crisman $\mathrm{G}$, Kerl H, et al. The prognosis of early mycosis fungoides is not influenced by phenotype and T-cell clonality. Br J Dermatol 2008;159:881-6.

20. Edinger JT, Clark BZ, Pucevich BE, et al. CD30 expression and proliferative fraction in nontransformed mycosis fungoides. Am J Surg Pathol 2009;33:1860-8.

21. Kim EJ, Lin J, Junkins-Hopkins JM, et al. Mycosis fungoides and sezary syndrome: an update. Curr Oncol Rep 2006;8:376-86.

22. Wada DA, Wilcox RA, Harrington SM, et al. Programmed death 1 is expressed in cutaneous infiltrates of mycosis fungoides and Sezary syndrome. Am J Hematol 2011;86:3257.

23. Cetinozman F, Jansen PM, Willemze R. Expression of Programmed Death-1 in Primary Cutaneous CD4-Positive Small/Medium-Sized Pleomorphic T-Cell Lymphoma, Cutaneous Pseudo-T-Cell Lymphoma, and Other Types of Cutaneous T-Cell Lymphoma. Am J Surg Pathol 2012;36:109-16.

24. Kantekure K, Yang Y, Raghunath P, et al. Expression patterns of the immunosuppressive proteins PD-1/CD279 and PD-L1/CD274 at different stages of cutaneous T-cell lymphoma/mycosis fungoides. Am J Dermatopathol 2012;34:126-8.

25. Sakthivel P, Gereke M, Bruder D. Therapeutic Intervention in Cancer and Chronic Viral Infections: Antibody Mediated Manipulation of PD-1/PD-L1 Interaction. Rev Recent Clin Trials 2012;7:10-23.

26. Kazakov DV, Belousova IE, Kacerovska D, et al. Hyperplasia of hair follicles and other adnexal structures in cutaneous lymphoproliferative disorders: a study of 53 cases, including so-called pseudolymphomatous folliculitis and overt lymphomas. Am J Surg Pathol 2008;32:1468-78. 


\section{Figure legends:}

Figure 1:

Annular and hypopigmented patches on the left lower leg.

Figure 2:

Epidermis infiltrated by small lymphocytes with chromatin dense nuclei. H\&E, original magnification, $100 \mathrm{X}$

Figure 3: Intraepidermal lymphocytes show nuclear atypia. H\&E, original magnification, $200 \mathrm{X}$

Figure 4:

Both intraepidermal and intradermal lymphocytes express CD3, Immunohistochemistry, original magnification, $100 \mathrm{X}$

Figure 5:

A. Intraepidermal and intradermal lymphocytes express beta-F1. B. Lack of expression of CD4 by intraepidermal lymphocytes. C. Intraepidermal lymphocytes are negative for CD8. D. Intraepidermal lymphocytes express PD-1. (Immunohistochemistry, original magnification, 100X A-D) 